\title{
Development of a curriculum for training in One Health analytical epidemiology at the University of Zambia
}

\author{
Authors: \\ J.B. Muma ${ }^{1}$ \\ Martin Simuunza \\ K. Mwachalimba ${ }^{1}$ \\ M. Munyeme ${ }^{1}$ \\ B. Namangala ${ }^{2}$ \\ C. Hankanga ${ }^{3}$ \\ G. Sijumbila ${ }^{4}$ \\ R. Likwa Ndonyo ${ }^{4}$ \\ Yona Sinkala ${ }^{5}$ \\ A. Mwanza \\ A. Simanyengwe Mweene ${ }^{1}$ \\ Affiliations: \\ ${ }^{1}$ Department of Disease \\ Control, University of \\ Zambia, Zambia \\ ${ }^{2}$ Department of Paraclinical \\ Studies, University of \\ Zambia, Zambia \\ ${ }^{3}$ Department of Clinical \\ Studies, University of \\ Zambia, Zambia \\ ${ }^{4}$ School of Medicine, \\ University of Zambia, Zambia \\ ${ }^{5}$ Department of Veterinary \\ and Livestock Development, \\ Ministry of Livestock and \\ Fisheries Development, \\ Zambia \\ Correspondence to: \\ Yona Sinkala \\ Email: \\ yona.sinkala@sacids.org \\ Postal address: \\ PO Box 30041, Lusaka, \\ Zambia \\ How to cite this course: \\ Muma, J.B., Simuunza, \\ M., Mwachalimba, K., \\ Munyeme, M., Namangala, \\ B., Hankanga, C. et al., \\ 2012, 'Development of \\ a curriculum for training \\ in $\mathrm{O}$ ne Health analytical \\ epidemiology at the \\ University of Zambia', \\ Onderstepoort Journal of \\ Veterinary Research 79(2), \\ Art. \#475, 4 pages. http:// \\ dx.doi.org/10.4102/ojvr. \\ v79i2. 475 \\ Note: \\ Proceedings of the \\ Conference of the Southern \\ African Centre for Infectious \\ Disease Surveillance 'One \\ Health' held at the National \\ Institute for Communicable \\ Diseases, Johannesburg, July \\ 2011.
}

Recently, the world has witnessed emergence of novel diseases such as avian influenza, HIV and AIDS, West Nile Virus and Ebola. The evolution of these pathogens has been facilitated mainly by a constantly evolving animal-human interface. Whilst infectious disease control was previously conceptualised as either public health or animal health related issues, the distinction between disciplinary foci have been blurred by multiple causal factors that clearly traverse traditional disciplinary divides. These multiple evolutionary pressures have included changes in land use, ecosystems, human-livestock-wildlife interactions and antibiotic use, representing novel routes for pathogen emergence. With the growing realisation that pathogens do not respect traditional epistemological divides, the 'One Health' initiative has emerged to advocate for closer collaboration across the health disciplines and has provided a new agenda for health education.

Against this background, the One Health Analytical Epidemiology course was developed under the auspices of the Southern African Centre for Infectious Diseases Surveillance by staff from the University of Zambia with collaborators from the London School of Hygiene and Tropical Medicine and the Royal Veterinary College in London. The course is aimed at equipping scientists with multidisciplinary skill sets to match the contemporary challenges of human, animal and zoonotic disease prevention and control. Epidemiology is an important discipline for both public and animal health. Therefore, this two-year programme has been developed to generate a cadre of epidemiologists with a broad understanding of disease control and prevention and will be able to conceptualise and design holistic programs for informing health and disease control policy decisions.

\section{Introduction}

In recent years, there has been increased discourse in the global health community on the subject of One Health (Meisser, Schelling \& Zinsstag 2011; Zinsstag et al. 2011). One Health is a systems approach to health in social-ecological systems incorporating the health of humans, animals and the environment. This has been prompted by the unprecedented emergency of novel zoonotic pathogens such as severe acute respiratory syndrome (SARS), avian influenza, West Nile virus, Rift Valley fever and Ebola, amongst others. Furthermore, it has been recognised by the World Health Organisation (WHO) that some of the classical zoonoses such as rabies, cysticercosis, trypanosomosis and bovine tuberculosis have not been given the appropriate attention (Briggs \& Hanlon 2007; Cleaveland, Haydon \& Taylor 2007; Fooks 2005; WHO 2005). Taylor, Latham and Woolhouse (2001) observed that out of 1415 human pathogens, 61\% are zoonotic. The increased risks of pathogen transmission from animals to humans have been attributed to a number of anthropogenic factors such as complex patterns of global change; the inextricable interconnection of humans through trade and travel; increased intensification of animal husbandry; the development of peri-urban systems for livestock production, increased domestication of wildlife in game ranches and encroachment of people and their livestock into wildlife areas (Zinsstag et al. 2011). The steady growth in the world population has resulted in limited space for human habitation, leading to continuous human encroachment on wildlife sanctuaries and this has amplified the risk of occurrence of new emerging diseases (Marcotty et al. 2009). A joint WHO, Food and Agriculture Organisation (FAO) and World Organisation for Animal Health (OIE) report on emerging zoonoses (2004), argued that zoonotic diseases are on the increase owing to shortfalls in public health infrastructure and policy, a paucity of public health scientific studies to answer questions and build expertise, and a lack of integrated human and animal health surveillance (WHO 2005).

The avian influenza pandemic demonstrated that no single profession can fight these disease threats single-handedly. Therefore, all players from human, veterinary and environmental health are indispensible in addressing the threats to health confronting our world. All these and

Copyright: (C) 2012. The Authors. Licensee: AOSIS OpenJournals. This work is licensed under the Creative Commons Attribution License. 
many other factors have drawn professions from different disciplines to engage in joint efforts in finding solutions to the threat that infectious diseases pose to human and animal survival (Powdrill, Nipp \& Rinderknecht 2010). Dedomon (2010) noted that, One Health is a paradigm that serves the needs of all and encourages the spirit of collaboration and scientific inquiry for the common good. Not only has the need for interdisciplinary participation been acknowledged in projects involving control of zoonoses (Marcotty et al. 2009; Roth et al. 2003; Zinsstag et al. 2007) but there has been a new awakening to change the way health professions are educated (Marcotty et al. 2009; Zinsstag et al. 2011). Consequently, we have seen increased advocacy for joint training in public health which has resulted in more learning institutions taking up the challenge of breaking traditional educational boundaries in health training. A good example of integrated training where the One Health concept has be embraced principally and structurally is the College of Veterinary Medicine, Nursing and Allied Health (CVMNAH) at Tuskegee University in the United States of America (Habtemariam 2011). The College is composed of the School of Veterinary Medicine (Animal Health) and the School of Nursing and Allied Health (Human Health) and is said:

to be the only one of its kind in the United States where Animal Health (Veterinary Medicine) and Human Health (Nursing \& Allied Health) are merged under one College within the framework of One Health-One Medicine. (Habtemariam 2011)

Further, in 2003, Kansas State University started to offer a new Master's program in One Health Public Health, with collaboration from Agriculture, Arts and Sciences, Human, Ecology and Veterinary Medicine (Michael 2010). More recently, Sokoine University of Agriculture introduced a course in One Health Molecular Biology aimed at increasing collaboration in diagnosis of infectious diseases, between the medical and veterinary sectors across sub-Saharan Africa and it envision to improvement of the quality of laboratory diagnosis and the standardisation of diagnostic methods across human and veterinary diagnostic laboratories, which is essential in facilitating international trade as advocated for by the Sanitary and Phytosanitary (SPS) Agreement under the World Trade Organisation (WTO). This paper discusses the development of the One Health Analytical Epidemiology at the University of Zambia, whose aim is to equip scientists with skills in analytical epidemiology for the efficient prevention and control of human, animal and zoonotic diseases.

\section{Development of the course curriculum}

The curriculum was developed by staff from the University of Zambia's Schools of Medicine and Veterinary Medicine. After the initial document was developed by the local staff, consultations were held with collaborators from the London School of Hygiene and Tropical Medicine (LSHTM), the Royal Veterinary College (RVC) in London. Further consultations were held with staff from the Sokoine University of Agriculture in Tanzania.

Curriculum development started with the formation of a joint working group comprising representatives from the Medical and Veterinary Schools of the University of Zambia (UNZA). The working group drew on expertise from epidemiology, public health and demography. The first committee meeting was held in September 2009 and involved brain storming on the modus operadi regarding the process of curriculum development. A work plan was formulated, where targets were set and responsibilities assigned to each member of the committee, which included the review of reference materials collected from collaborating institutions. Subsequently, key courses were identified and a draft course outline proposed (Table 1). Each member of the working group was assigned to develop a structure for the course they were comfortable with. After a series of meetings, a zero-draft was developed and circulated amongst members of the group for review and comments. Finally, a four day workshop was organised for in-depth review of the zero draft. The output of the workshop was a working document that was ready for external review.

External consultations were in two forms. Firstly, there was soliciting for course materials of related programmes from collaborating institutions and personal discussions with the expert in the identified fields. Materials were collected from the LSHTM and the RVC in London, and Muhimbili University of Health and Allied Sciences (MUHAS) in Tanzania. The Curriculum for MSc in Public Health currently running at the School of Medicine at UNZA was also included in the reference material. Secondly, a visit was made to the UK in April 2011, with the main purpose of presenting the working document to collaborators in the North and receiving comments. A series of meetings were held of small groups of specialists in epidemiology and economics at both LSHTM and the RVC. The visits presented us with an opportunity to discuss the curriculum with

TABLE 1: Programme structure for the One Health Analytical Epidemiology and distribution of courses by semester.

\begin{tabular}{llll}
\hline Semester & Course name & Description & Hours \\
\hline Semester 1 & Research Methodology and Computer Applications & Core course & 117 \\
& Principles of Epidemiology and Biostatistics & Core course & Core course \\
& Disease Surveillance and Risk Analysis & Core course & 120 \\
& Emerging and Re-emerging Disease & Core course & 117 \\
Semester 2 & Infectious Disease Modelling and Geographical Information System & Core course & 123 \\
& Advanced Statistical Methods in Epidemiology & Core course & 117 \\
& One Health Medicine and Globalisation & Elective course & 91 \\
& Health Economics, Policy, Monitoring and Evaluation & Elective course & 91 \\
& Molecular Epidemiology and Bioinformatics & & \\
\hline
\end{tabular}


leading experts and improve curriculum design. During this final visit, the outline of the draft curriculum and its contents were thoroughly revised and modified. Two of the proposed courses were re-conceptualised and renamed and another two were merged in order to conform to the One Health concept. The visit also presented an opportunity to learn and share knowledge on the techniques of developing the curriculum and somehow strengthened the interactions with various professionals of different expertise in the field of medicine and veterinary medicine.

Upon returning from the UK, a visit was made to the Sokoine University of Agriculture in Tanzania where further consultations with regional expertise were held. After this external review, the curriculum was finalised and presented to the Joint School of Veterinary Medicine and School of Medicine Board of Studies and then subsequently to the University of Zambia Senate for final approval in June 2011.

\section{Structure of the drafted curriculum}

The output of the discussions, workshops and interinstitutional consultations resulted into the Curriculum for the Master of Science in One Heath Analytical Epidemiology that will be offered by the University of Zambia, starting from September 2011. The programme is structured such that by the end of the training, students of MSc One Health Analytical Epidemiology should be able to do the following:

- demonstrate knowledge of the concept of 'One Health' and its application in the development of health policy and the control and prevention of infectious diseases

- demonstrate knowledge on how interactions between human and animal populations and environmental changes can lead to emergency and re-emerging of infectious diseases

- plan, undertake and analyse data from a research project concerning human, animal and zoonotic diseases and be able to monitor and evaluate activities for policy and programme development

- apply a scientific style of writing in the presentation of research

- apply economic and socio-economic concepts and methods in the design, implementation and evaluation of health delivery services

- determine the factors affecting the spread of disease through human and animal populations and be able to prevent or control such spread.

The courses that the students will have to undertake in order for the above stated learning outcomes to be achieved are shown in Table 1. It is hoped that at the end of their training students will have acquired skills in analytical epidemiology for efficient prevention and control of human, animal and zoonotic diseases.

The programme shall comprise two parts, a taught component executed by coursework in the first year (Part I) and a research project that will culminate in the submission of a dissertation in the second year (Part II). The two parts shall be undertaken consecutively. The first part (Part I) of the programme shall be undertaken over a period of two semesters (Semesters 1 and 2) of fulltime study and shall comprise:
- course work as required by the School Board of Graduates Studies (http:/ / www.unza.zm)

- lectures, practicals and tutorials as well as participation in field trips and seminars

- continuous assessment which will include written tests, assignments, laboratory or field reports and seminar presentations

- a written examination at the end of each semester

- submission of a research proposal for part II of the programme for approval.

The second part (Part II) of the program shall be undertaken over a period of two semesters (Semesters 3 and 4) of fulltime study and shall comprise supervised research work culminating in the submission of a dissertation. The topic (research proposal) of the dissertation shall be guided by the One Health theme and shall be approved by the School Postgraduate Committee in the last seven weeks of the second semester of Part I. For successful implementation of the course, no student will be permitted to proceed to Part II of the degree program unless he or she has satisfied the requirement of Part I.

\section{Teaching strategies}

Course delivery will mainly be done by experts from the Schools of Medicine and Veterinary at the University of Zambia. Experts from other southern African academic and research institutions within the Southern African Centre for Infectious Disease Surveillance (SACIDS) consortium as well as staff from collaborating research institutions in industrialised countries, especially the RVC and LSHTM will also participate in course delivery. This will create a blend of professional knowledge and skills in epidemiology and One Health that will provide a unique learning environment.

\section{Career opportunities for graduates}

Students graduating with an MSc in One Health Analytical Epidemiology would be professionals with international competence to work in the local and regional markets in training and research institutions, government public health system and international bodies tasked with management of human and animal health such as WHO, OIE, FAO et cetera.

\section{Admission criteria}

All applications will be considered through the Directorate of Research and Graduate Studies of the University of Zambia. The following shall be eligible to apply for the Masters degree in Analytical Epidemiology at the University of Zambia:

- Graduates from any recognised University in the field of Biological Sciences, Medicine, Veterinary Medicine/ Science and any other related field of study.

- The minimum requirement for medical and veterinary candidates is a first degree with at least B grade for Epidemiology, Statistics or Community Medicine. Applicants must also have obtained a minimum grade of $B$ in A level mathematics.

- Medical and veterinary graduates with at least one year of related medical or veterinary experience will have an added advantage. 
- Graduates from Biological Sciences must have at least a Merit grade and those with at least two years of postqualifying experience will have an added advantage.

- Candidates wishing to pursue any specific course(s) under this programme may be considered, and will be awarded a certificate upon successful completion. Such students shall not be eligible for the award of the MSc. in One Health Analytical Epidemiology.

- In general, rules and regulations prescribed by the Directorate of Research and Graduate Studies at the University of Zambia shall apply (http:/ / www.unza.zm).

We have developed a Master of Science programme in One Health Analytical Epidemiology which is aimed at furthering the holistic approach in combating the threat of infectious diseases using the combined resources of human and veterinary professionals and allied sciences. This has come out of the recognition that the control of diseases in the Southern African Development Community (SADC) region requires acquisition and strengthening of human knowledge and skills by training professionals with competence in One Health and epidemiology. Thus, graduates of this training programme will not only be epidemiologists, but will also have an understanding of the concept of One Health.

This curriculum is tailored towards epidemiological understanding of disease dynamics and thus does not claim to offer all that is needed to be learnt on the subject of 'One Health'. However, it is acknowledged that epidemiology is a key discipline in effective management of human, animal and environmental health. In order to make the programme more applicable, other vital subjects such as global health and economics have been fused in so as to supplement what is ordinarily known as classical epidemiology. Collectively, these tools are meant to help in understanding the close association that exists between human and animal health as evidenced in the recent occurrence of the H1N1 Avian Influenza pandemic. The programme will therefore emphasise the need for inter-sectoral collaboration in disease surveillance, epidemic disease preparedness and response as well as development of enabling policy platforms, across the human, animal and eco-health sectors. It has become apparent that the responsibility to ensure public health, especially as it pertains to the risk of emerging and re-emerging zoonoses, is a shared responsibility of professionals in the human and veterinary medicine and other allied sciences such as ecology (Michael 2010).

Marcotty et al. (2009) strongly encouraged collaboration between the veterinary and the medical sectors, in the diagnosis, monitoring and control of zoonotic brucellosis and tuberculosis. These authors further, added that useful collaborations could be nurtured at undergraduate- and postgraduate-training levels, through, for example, common public-health modules or courses. This programme has been designed to train a new generation of world class scientists who will serve to address the heavy burden and threat of emerging and re-emerging infectious diseases in Africa that greatly hamper public health and animal health and thus socio-economic development of developing countries (WHO 2005). The successful implementation of the programme strongly depends on support from other SACIDS consortium universities in southern Africa as well as the LSHTM, RVC and other internationally reputable institutions.

\section{Conclusion}

It is hoped that the training programme will create increased collaboration between professions in medical, veterinary and allied sciences and create a platform for sharing their knowledge and resources to better promote human, animal and environmental health. The medical profession would, benefit greatly from an improved knowledge and understanding of the epidemiology of zoonotic diseases whilst the veterinary sector would, have a better appreciation of what is expected from them, in terms of controlling the zoonoses in order to assure public health.

\section{Acknowledgement}

The Wellcome Trust is thanked for funding the development of the curriculum through SACIDS. The curriculum development was part of wider SACIDS Consortium projects under the framework of the One Heath Concept. We are further grateful for the support we received from the London International Development Centre, London School of Hygiene and Tropical Medicine, the Royal Veterinary College, Sokoine School of Agriculture, Muhimbili University of Health and Allied Sciences and the University of Zambia. We would also like to thank Professor Kenny Samui for his contribution to the successful development of this curriculum.

\section{References}

Briggs, D. \& Hanlon, C.A., 2007, 'World Rabies Day: focusing attention on a neglected disease', Veterinary Record 161, 288-289. http://dx.doi.org/10.1136/ vr.161.9.288, PMid:17766802

Cleaveland, S., Haydon, D.T. \& Taylor, L., 2007, 'Overviews of pathogen emergence: which pathogens emerge, when and why?', Current Topics in Microbiology and Immunology 315, 85-111. http://dx.doi.org/10.1007/978-3-540-70962-6_5

Cleaveland, S., Laurenson, M.K. \& Taylor, L.H., 2001, 'Diseases of humans and their domestic mammals: pathogen characteristics, host range and the risk of emergence', Philosophical Transactions of the Royal Society B: Biological Scien
356, 991-999. http://dx.doi.org/10.1098/rstb.2001.0889, PMid:11516377

Dedomon, E.R., 2010, 'The One Health Initiative through a 50-Year Lens', One Health News Letter Fall, 3-5.

Fooks, A.R., 2005, 'Rabies remains a "neglected disease"', EuroSurveillance 10, $211-$ 212. PMid: 16972345

Habtemariam, 2011, The College of Veterinary Medicine, Nursing and Allied Health viewed 31 August 2011 from, http://www.tuskegee.edu/academics/colleges/ cvmnah/office_of_the_dean_-_cvmnah.aspx

Marcotty, T., Matthys, F., Godfroid, J., Rigouts, L., Ameni, G., Gey van Pittius, N. et al., 2009, 'Zoonotic tuberculosis and brucellosis in Africa: Neglected zoonoses or minor public-health issues? The outcomes of a multi-disciplinary workshop' Annals of Tropical Medicine and Parasitology 103, 401-411. http://dx.doi. org/10.1179/136485909X451771, PMid:19583911

Meisser, A., Schelling, E. \& Zinsstag, J., 2011, 'One health in Switzerland: a visionary concept at a crossroads?', Swiss Medical Weekly 141, 13201.

Michael, B., 2010, 'An innovative approach to graduate Public Health education', One Health Newsletter Fall, 1-2.

Powdrill, T.F., Nipp, T.L. \& Rinderknecht, J.L., 2010, 'One Health approach to influenza: Assessment of critical issues and options', Emerging Infectious Diseases 16, e1. $\mathrm{http}: / / \mathrm{dx}$.doi.org/10.3201/eid1608.100673, PMid:20678310

Roth, F., Zinsstag, J., Orkhon, D., Chimed-Ochir, G., Hutton, G., Cosivi, O. et al., 2003 'Human health' benefits from livestock vaccination for brucellosis: case study', Bulletin of World Health Organisation 81, 867-876. PMid:14997239

Taylor, L.H., Latham, S.M. \& Woolhouse, M.E., 2001, 'Risk factors for human disease emergence', Philosophical Transactions of the Royal Society B: Biological Sciences 356, 983-989. http://dx.doi.org/10.1098/rstb.2001.0888, PMid:11516376

WHO, 2005, The control of neglected zoonotic diseases: A route to poverty alleviation, Geneva, Switzerland

Zinsstag, J., Schelling, E., Roth, F., Bonfoh, B., De Savigny, D. \& Tanner, M., 2007 'Human benefits of animal interventions for zoonosis control', Emerging Infectious Diseases 13, 527-531. http://dx.doi.org/10.3201/eid1304.060381, PMid:17553265

Zinsstag, J., Schelling, E., Waltner-Toews, D. \& Tanner, M., 2011, "From "One Medicine" to "One Health" and systemic approaches to health and well-being', Preventive Veterinary Medicine 101,
PMid:20832879 